\title{
Brain Natriuretic Peptide and Body Fluid Composition in Patients with Chronic Kidney Disease: A Cross-Sectional Study to Evaluate the Relationship between Volume Overload and Malnutrition
}

\author{
Yasushi Ohashi $^{a}$ Akinobu Saito $^{b}$ Keisuke Yamazaki ${ }^{a}$ Reibin Tai ${ }^{b}$

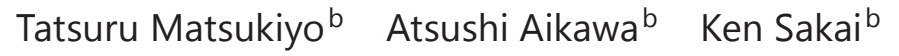 \\ a Department of Nephrology, Sakura Medical Center, School of Medicine, Toho University, \\ Chiba, and ${ }^{b}$ Department of Nephrology, Omori Medical Center, School of Medicine, Toho \\ University, Tokyo, Japan
}

\section{Key Words}

Bioimpedance analysis · Brain natriuretic peptide · Chronic kidney disease · Fluid overload · Malnutrition

\begin{abstract}
Background/Aim: Fluid volume overload occurs in chronic kidney disease (CKD), leading to the compensatory release of natriuretic peptides. However, the elevated cardiac peptides may also be associated with malnutrition as well as volume overload. Methods: Body fluid composition was measured in 147 patients with CKD between 2009 and 2015, and its relationship to brain natriuretic peptide (BNP) levels was examined. Body fluid composition was separated into three components: (a) a water-free mass consisting of muscle, fat, and minerals; (b) intracellular water (ICW) content, and (c) extracellular water (ECW) content. Excess fluid mass was calculated using Chamney's formula. Results: The measured BNP levels in the tertile groups were $10.9 \pm 5.4,36.3 \pm 12.5$, and $393 \pm 542 \mathrm{pg} / \mathrm{ml}$, respectively. Patients in a higher log-transformed BNP level tertile were more likely to be older, to have a higher frequency of cardiac comorbidities, pulse pressure, C-reactive protein levels, and proteinuria, and to have lower serum sodium, kidney function, and serum albumin ( $p<0.05)$. In body fluid composition, decreased body mass was significantly associated with the ECW-to-ICW ratio in relation to the downward ICW slope $(r=-0.235, p=0.004)$ and was strongly correlated with excess fluid mass $(r=-0.701, \mathrm{p}<0.001)$. The ECW-to-ICW ratio and excess fluid mass was independently associated with the BNP levels. Conclusion: Fluid volume imbalance between intra- and extracellular water regulated by decreased cell mass was independently associated with BNP levels, which may explain the reserve capacity for fluid accumulation in patients with CKD.
\end{abstract}




\section{CardioRenal Medicine}

\section{Introduction}

Cardiovascular disease is prevalent in patients with chronic kidney disease (CKD) and is the most common fatal disease in these patients $[1,2]$. Sodium retention typically occurs as CKD progresses, leading to extracellular fluid volume expansion with the compensatory release of natriuretic peptides due to stretching of the cardiac wall. Additionally, these elevated cardiac peptides might be associated with malnutrition as well as fluid volume overload [3, 4]. Therefore, we hypothesized that elderly and malnourished patients with CKD would be more susceptible to volume overload compared with well-nourished patients. Among patients undergoing dialysis, those with low body mass had a higher prevalence of hypertension, poorer control of hypertension, and greater left ventricular hypertrophy [5]. An association between protein-energy wasting and $\mathrm{N}$-terminal pro-brain natriuretic peptide had previously been reported [6].

In the general population, the hydration component comprises $73.3 \%$ of the fat-free mass and is distributed between the intracellular water (ICW) and extracellular water (ECW) at a ratio of 62:38 [7]. However, the fluid volume balance between the ICW and ECW might change when the hydration component gradually decreases with age or muscle mass loss, primarily due to cell volume loss [8]. The ECW-to-ICW ratio might explain the reserve capacity for volume overload in patients with CKD.

In the present study, we aimed to (1) assess the fluid volume balance between ICW and ECW and excess fluid mass based on the body mass and (2) determine the association between body fluid composition and brain natriuretic peptide (BNP) levels in patients with CKD.

\section{Subjects and Methods}

\section{Study Design}

Body fluid composition and plasma BNP values were measured in 158 nondialysis patients with CKD (age $\geq 20$ years) by using a multifrequency bioelectrical impedance analysis (MFBIA) instrument (Inbody S20 ${ }^{\circledR}$; Biospace Co. Ltd., Seoul, South Korea) between October 2009 and May 2015. BNP was determined by using an enzyme-linked immunosorbent assay (TOSOH CORPORATION, Tokyo, Japan). We identified 147 patients with complete clinical data, and simultaneously assessed their age, sex, underlying disease, presence or absence of cardiac comorbidities, anthropometric measurements, blood pressure, and prescribed diuretic and antihypertensive agents. Cardiac comorbidities were defined as a composite of hospital-treated myocardial infarction or coronary intervention, hospital-treated heart failure, surgical-treated valvular disease, or medical-treated arrhythmia. The surveyed patients were categorized according to the tertile of the log-transformed plasma level of BNP, and data for the total cholesterol, triglyceride, fasting blood glucose, C-reactive protein, estimated glomerular filtration rate (eGFR), and ratio of urinary protein to creatinine in a random urine sample (UPCR) were extracted from the electronic medical records on the same day. The patients were classified as underweight, normal, overweight, or obese according to the body mass index (BMI) cutoffs of <18.5, 18.5-24.9, 25.0-29.9 and $\geq 30$ [9]. The stage of CKD was classified based on the GFR category [1], and the eGFR was calculated according to the revised formula for Japanese patients using the Modification of Diet in Renal Disease method [10] as follows: $194 \times$ creatinine $^{-1.094} \times$ age $^{-0.287}(\times 0.739$ for women). The geriatric nutritional risk index, a simplified nutritional screening index, was calculated as follows: $(14.89+$ albumin $[\mathrm{g} / \mathrm{dl}])+(41.7 \times$ body weight/ideal body weight of BMI 22) [11]. Treatment-resistant high blood pressure was defined as a systolic blood pressure $\geq 140 \mathrm{~mm} \mathrm{Hg}$ or diastolic blood pressure $\geq 90 \mathrm{~mm} \mathrm{Hg}$ in patients without proteinuria and as a systolic blood pressure $\geq 130 \mathrm{~mm} \mathrm{Hg}$ or diastolic blood pressure $\geq 80 \mathrm{~mm} \mathrm{Hg}$ in patients with proteinuria who received three or more hypertension medications, including diuretics. Blood pressure was considered treatment resistant if the patient took four or more drugs for control $[1,12]$.

Assessment of Body Fluid Composition

Standard MFBIA was performed with the patient lying in the supine position on a flat nonconductive bed for at least $15 \mathrm{~min}$. We used a segmental MFBIA instrument with eight tactile electrodes for body fluid 


\section{CardioRenal Medicine}

\begin{tabular}{l|l}
\hline Cardiorenal Med 2016;6:337-346 \\
\hline DOI: 10.1159/000447024 & $\begin{array}{l}\text { @ 2016 S. Karger AG, Basel } \\
\text { www.karger.com/crm }\end{array}$ \\
\hline
\end{tabular}

Ohashi et al.: Brain Natriuretic Peptide and Body Fluid Composition in CKD

composition measurements. The microprocessor-controlled switches and impedance analyzer were activated and the segmental resistances of the arms, trunk, and legs were measured at four frequencies $(5,50$, 250, and $500 \mathrm{kHz}$ ). The measured body fluid composition was separated into the following three components: (a) water-free mass consisting of proteins, fat, and minerals, (b) ICW content, and (c) ECW content. The normal healthy reference range of the ECW-to-total body water (TBW) ratio was defined as 0.36-0.40 [13]. Excess fluid mass, normally hydrated lean tissue mass, and normally hydrated adipose tissue mass were calculated according to Chamney's formula [14] (suppl. fig. S1; for all online suppl. material, see www. karger.com/doi/10.1159/000447024). In addition, we used the ECW-to-TBW ratio and dry mass index (DMI) calculated by water-free mass divided by the square of the body height in the association between hydration status and nutritional status [15].

\section{Statistical Analyses}

The data were analyzed by using JMP 9.0 statistical software (SAS Institute, Inc., Cary, N.C., USA). The measured values are expressed as the means \pm standard deviations and percentages. Statistical significance was assessed by using a linear regression model to compare the mean values of possible risk factors among the tertile groups for continuous variables and by using Pearson's $\chi^{2}$ test for categorical variables. Correlations between variables were determined by using the Pearson product-moment correlation coefficient. Linear regression analyses were used to identify associations between the log-transformed BNP levels and demographic factors. Explanatory variables that had a significant correlation $(\mathrm{p}<0.1)$ to the log-transformed BNP levels were analyzed by using multivariate analysis to evaluate independent associations. p values $<0.05$ were considered statistically significant.

\section{Results}

Population Characteristics at the Time of Bioimpedance Analysis

The population characteristics of the subjects [98 men and 49 women; mean age $67.0 \pm$ 13.0 years; median eGFR (10-90th percentile) 22.7 (5.5-56.9) $\mathrm{ml} / \mathrm{min}$ per $\left.1.73 \mathrm{~m}^{2}\right]$, including the log-transformed plasma BNP levels by tertiles, are shown in table 1 . The tertile values were classified as $<3.03,3.03-4.16$, and $\geq 4.17$, and the averages of the measured BNP levels in the three groups were $10.9 \pm 5.4,36.3 \pm 12.5$, and $393 \pm 542 \mathrm{pg} / \mathrm{ml}$, respectively. Patients in a higher tertile of the log-transformed BNP levels were likely to be older, have a higher frequency of cardiac comorbidities, a higher pulse pressure, higher C-reactive protein and UPCR levels, a higher prevalence of furosemide use as well as of other antihypertensives besides renin-angiotensin-aldosterone system inhibitors, and they were likely to have a lower BMI, lower serum sodium and albumin levels, lower kidney function, total cholesterol and triglyceride levels, as well as a lower geriatric nutritional risk index $(p<0.05)$. The $67.3 \%$ of patients in the highest tertile were categorized as CKD stage G5. In body fluid composition analysis, the percentage of the ICW content in body weight and the percentage of the ECW content in body weight increased along with decreasing water-free mass in patients in a higher tertile of the log-transformed BNP levels $(\mathrm{p}<0.001)$.

\section{Body Fluid Composition by Tertile of the Log-Transformed Plasma Level of BNP}

The associations between the log-transformed BNP levels and body fluid composition are shown in figure 1. The water-free mass decreased with elevated BNP levels $(r=-0.48, \mathrm{p}<$ $0.001)$. The ICW slope tended to decrease as the BNP levels increased $(r=-0.27, \mathrm{p}=0.009)$; however, the ECW content tended to be constant $(r=-0.17, \mathrm{p}=0.045)$. The shift in the balance between the ICW and ECW led to an increase in the ECW-to-ICW ratio, which was significantly associated with the BNP levels ( $r=0.59, \mathrm{p}<0.001)$ (fig. 1). Comparatively, normally hydrated adipose tissue mass decreased with increased BNP levels $(r=-0.42, \mathrm{p}<0.001)$; moreover, excess fluid mass was associated with BNP levels ( $r=0.60, \mathrm{p}<0.001$ ) (fig. 1$)$. 
Table 1. Sample characteristics according to tertile of the log-transformed plasma level of BNP at the time of bioimpedance analysis

\begin{tabular}{|c|c|c|c|c|}
\hline \multirow[t]{2}{*}{ Sample characteristics } & \multicolumn{3}{|c|}{ Log-transformed plasma level of BNP } & \multirow[t]{2}{*}{$\mathrm{p}$ for trend } \\
\hline & $\begin{array}{l}\text { tertile } 1(<3.03) \\
(n=49)\end{array}$ & $\begin{array}{l}\text { tertile } 2(3.03-4.16) \\
(\mathrm{n}=49)\end{array}$ & $\begin{array}{l}\text { tertile } 3(\geq 4.17) \\
(\mathrm{n}=49)\end{array}$ & \\
\hline Age, years & $61.5 \pm 13.8$ & $67.3 \pm 10.8$ & $72.2 \pm 12.2$ & $<0.001$ \\
\hline Male sex, n (\%) & $35(71.4)$ & $32(65.3)$ & $31(63.3)$ & 0.67 \\
\hline Diabetes mellitus, n (\%) & $14(28.6)$ & $14(28.6)$ & $13(26.5)$ & 0.97 \\
\hline Presence of cardiac comorbidities, n (\%) & $5(10.2)$ & $15(30.6)$ & $27(55.1)$ & $<0.001$ \\
\hline BMI & $27.5 \pm 4.2$ & $25.0 \pm 3.2$ & $23.3 \pm 3.7$ & $<0.001$ \\
\hline Systolic blood pressure, mm Hg & $130 \pm 18$ & $132 \pm 19$ & $130 \pm 21$ & 0.90 \\
\hline Diastolic blood pressure, $\mathrm{mm} \mathrm{Hg}$ & $77 \pm 13$ & $73 \pm 13$ & $69 \pm 12$ & 0.002 \\
\hline Pulse pressure, $\mathrm{mm} \mathrm{Hg}$ & $53 \pm 13$ & $58 \pm 16$ & $60 \pm 19$ & 0.031 \\
\hline Resistant high blood pressure, n (\%) & $16(32.7)$ & $17(34.7)$ & $25(51.0)$ & 0.14 \\
\hline Serum sodium, mEq/l & $140.3 \pm 2.6$ & $139.8 \pm 3.0$ & $138.1 \pm 4.2$ & 0.002 \\
\hline Serum potassium, mEq/l & $4.5 \pm 0.5$ & $4.6 \pm 0.6$ & $4.4 \pm 0.7$ & 0.30 \\
\hline Serum creatinine, mg/dl & $2.05 \pm 1.38$ & $3.30 \pm 3.36$ & $5.36 \pm 3.88$ & $<0.001$ \\
\hline $\mathrm{eGFR}_{\mathrm{MDRD}}, \mathrm{ml} / \mathrm{min}$ per $1.73 \mathrm{~m}^{2}$ & $37 \pm 23$ & $29 \pm 19$ & $15 \pm 10$ & $<0.001$ \\
\hline \multicolumn{5}{|l|}{ GFR categories in KDIGO 2012} \\
\hline G1 or $2, n(\%)$ & $7(14.3)$ & $3(6.1)$ & $0(0.0)$ & \multirow[t]{4}{*}{$<0.001$} \\
\hline G3a or G3b, n (\%) & $17(34.7)$ & $19(38.8)$ & $4(8.2)$ & \\
\hline $\mathrm{G} 4, \mathrm{n}(\%)$ & $16(32.7)$ & $12(24.5)$ & $12(24.5)$ & \\
\hline G5, n (\%) & $9(18.4)$ & $15(30.6)$ & $33(67.3)$ & \\
\hline Serum albumin, mg/dl & $4.0 \pm 0.5$ & $3.9 \pm 0.5$ & $3.5 \pm 0.5$ & $<0.001$ \\
\hline Total cholesterol, mg/dl & $186 \pm 45$ & $177 \pm 43$ & $168 \pm 38$ & 0.048 \\
\hline Triglyceride, $\mathrm{mg} / \mathrm{dl}$ & $180 \pm 108$ & $167 \pm 98$ & $126 \pm 73$ & $<0.001$ \\
\hline Fasting blood glucose, $\mathrm{mg} / \mathrm{dl}$ & $120 \pm 36$ & $121 \pm 44$ & $132 \pm 48$ & 0.14 \\
\hline C-reactive protein, $\mathrm{mg} / \mathrm{dl}$ & $0.2 \pm 0.2$ & $0.2 \pm 0.5$ & $0.5 \pm 1.0$ & 0.030 \\
\hline UPCR, g/g.Cr & $1.6 \pm 3.0$ & $2.0 \pm 3.4$ & $2.8 \pm 2.7$ & 0.010 \\
\hline Brain natriuretic peptide, $\mathrm{pg} / \mathrm{ml}$ & $10.9 \pm 5.4$ & $36.3 \pm 12.5$ & $393 \pm 542$ & $<0.001$ \\
\hline Geriatric nutritional risk index & $111 \pm 11$ & $106 \pm 9$ & $96 \pm 12$ & $<0.001$ \\
\hline Total body water, l & $34.9 \pm 8.3$ & $33.2 \pm 6.7$ & $31.5 \pm 7.7$ & 0.005 \\
\hline$\%$ in body weight & $48.5 \pm 6.6$ & $50.6 \pm 5.9$ & $53.0 \pm 7.2$ & $<0.001$ \\
\hline $\mathrm{ICW}_{\mathrm{BIA}}, \mathrm{l}$ & $21.2 \pm 5.2$ & $19.9 \pm 4.0$ & $18.7 \pm 4.7$ & $<0.001$ \\
\hline$\%$ in body weight & $29.0 \pm 4.3$ & $30.4 \pm 3.6$ & $31.4 \pm 4.3$ & $<0.001$ \\
\hline $\mathrm{ECW}_{\mathrm{BIA}}, \mathrm{l}$ & $13.8 \pm 3.2$ & $13.2 \pm 2.7$ & $12.8 \pm 3.0$ & 0.045 \\
\hline$\%$ in body weight & $19.1 \pm 2.4$ & $20.2 \pm 2.5$ & $21.6 \pm 3.0$ & $<0.001$ \\
\hline Water-free contents, kg & $37.4 \pm 10.4$ & $32.5 \pm 7.2$ & $28.0 \pm 7.3$ & $<0.001$ \\
\hline$\%$ in body weight & $51.5 \pm 6.6$ & $49.4 \pm 5.9$ & $47.0 \pm 7.2$ & $<0.001$ \\
\hline Ratio of $\mathrm{ECW}_{\mathrm{BIA}} / \mathrm{ICW}_{\mathrm{BIA}}$ & $0.65 \pm 0.03$ & $0.66 \pm 0.02$ & $0.69 \pm 0.03$ & $<0.001$ \\
\hline Furosemide, n (\%) & $8(16.3)$ & $10(20.4)$ & $27(55.1)$ & $<0.001$ \\
\hline Other diuretics, n (\%) & $8(16.3)$ & $10(20.4)$ & $9(18.4)$ & 0.89 \\
\hline ACE inhibitors, $\mathrm{n}(\%)$ & $10(20.4)$ & $10(20.4)$ & $4(8.2)$ & 0.55 \\
\hline AT1 receptor blockers, n (\%) & $41(83.7)$ & $34(69.4)$ & $23(46.9)$ & $<0.001$ \\
\hline Other antihypertensives & $31(63.3)$ & $32(65.3)$ & $46(93.9)$ & $<0.01$ \\
\hline
\end{tabular}

$\mathrm{eGFR}_{\mathrm{MDRD}}=$ Estimated glomerular filtration rate by the Modification of Diet in Renal Disease method; KDIGO = Kidney disease: improving global outcomes; BIA = bioelectrical impedance analysis; ACE inhibitors = angiotensinconverting enzyme inhibitors; AT1 receptor blockers = angiotensin II type 1 receptor blockers. 


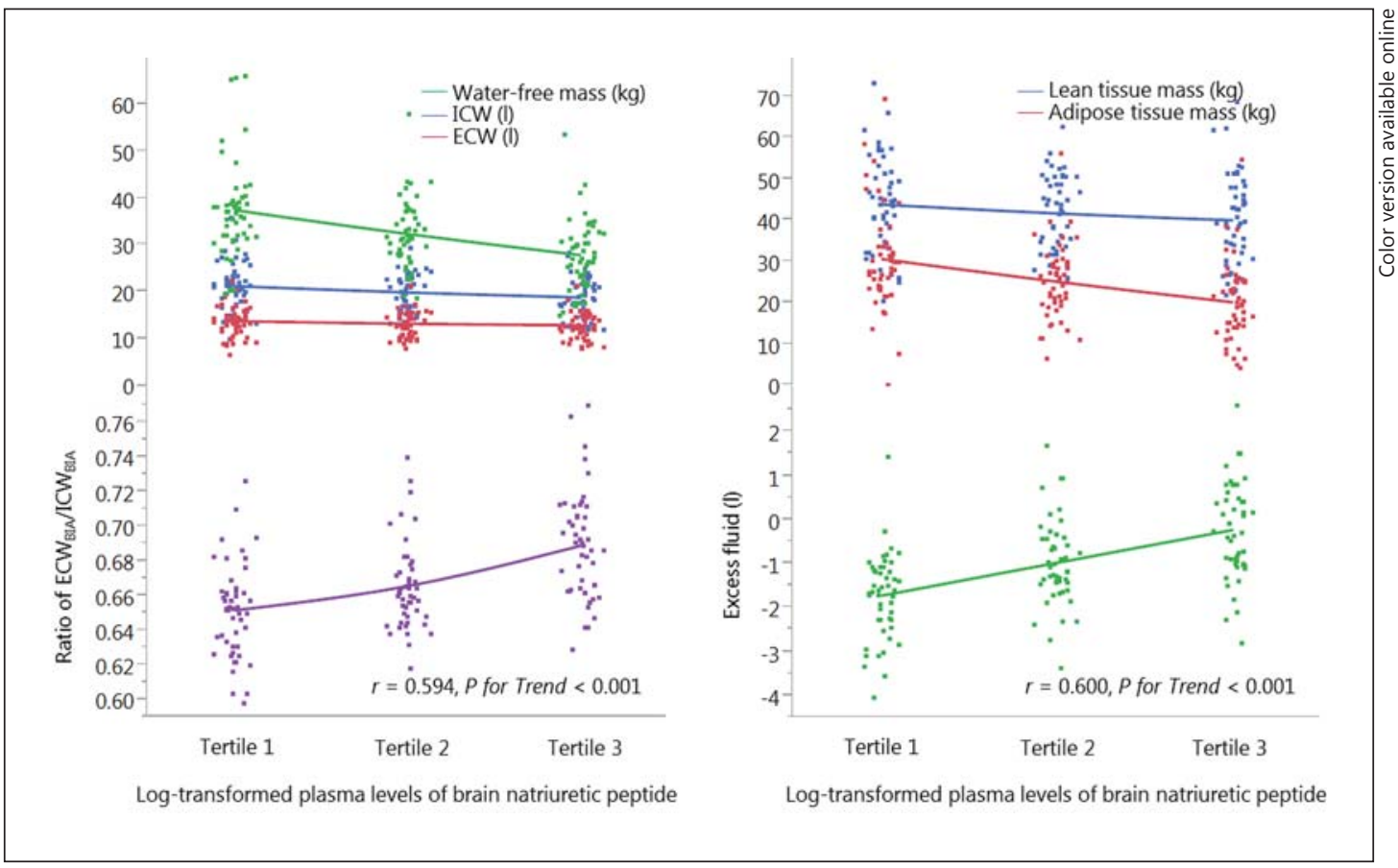

Fig. 1. Body fluid composition by tertile of the log-transformed plasma level of BNP. BIA = Bioelectrical impedance analysis.

Association between BMI and the Ratio of ECW to ICW, Excess Fluid Mass, and the Log-Transformed Plasma Level of BNP

The ECW-to-ICW ratio tended to increase as the BMI decreased, especially in leaner patients $(r=-0.24, \mathrm{p}=0.004$; fig. 2$)$. The slope of the ECW-to-ICW ratio was less sharp in obese patients. An association was observed between lower BMI and the log-transformed BNP levels $(r=-0.27, \mathrm{p}=0.001)$. Notably, excess fluid mass had a strong negative correlation with BMI $(r=-0.70, \mathrm{p}<0.001)$.

Correlations between the Log-Transformed Plasma BNP Levels and the Percentage of Components of the Body Fluid Composition in the Body Weight

The correlations between the log-transformed BNP levels and the percentage of body fluid components in the body weight are shown in figure 3 . The percentage of water-free mass in the body weight was negatively correlated with the BNP levels $(r=-0.31, \mathrm{p}<0.001)$. Symmetrically, the percentage of the ECW content in the body weight was positively correlated with the BNP levels $(r=0.42, \mathrm{p}<0.001)$, although this difference was less noticeable in the percentage of the ICW content in the body weight $(r=0.22, \mathrm{p}<0.01)$. Therefore, the ratio of the ECW to ICW and the percentage of excess fluid mass in the body weight had the highest correlation with the BNP levels in those components of body fluid composition.

\section{Associations between the DMI and the Ratio of the ECW to TBW with the Measured BNP}

Levels

The measured BNP levels in six groups classified according to DMI tertile and presence or absence of the ratio of the ECW to TBW $\geq 0.40$ are shown in figure 4. The average BNP level tended to be higher in patients with an ECW-to-TBW ratio $\geq 0.40$, especially in those in the 


\section{CardioRenal Medicine}

Fig. 2. Association between BMI classification and the ratio of the ECW to ICW, excess fluid mass, and the log-transformed plasma level of BNP. BIA = Bioelectrical impedance analysis.

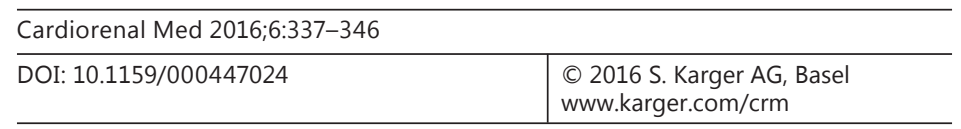

Ohashi et al.: Brain Natriuretic Peptide and Body Fluid Composition in CKD

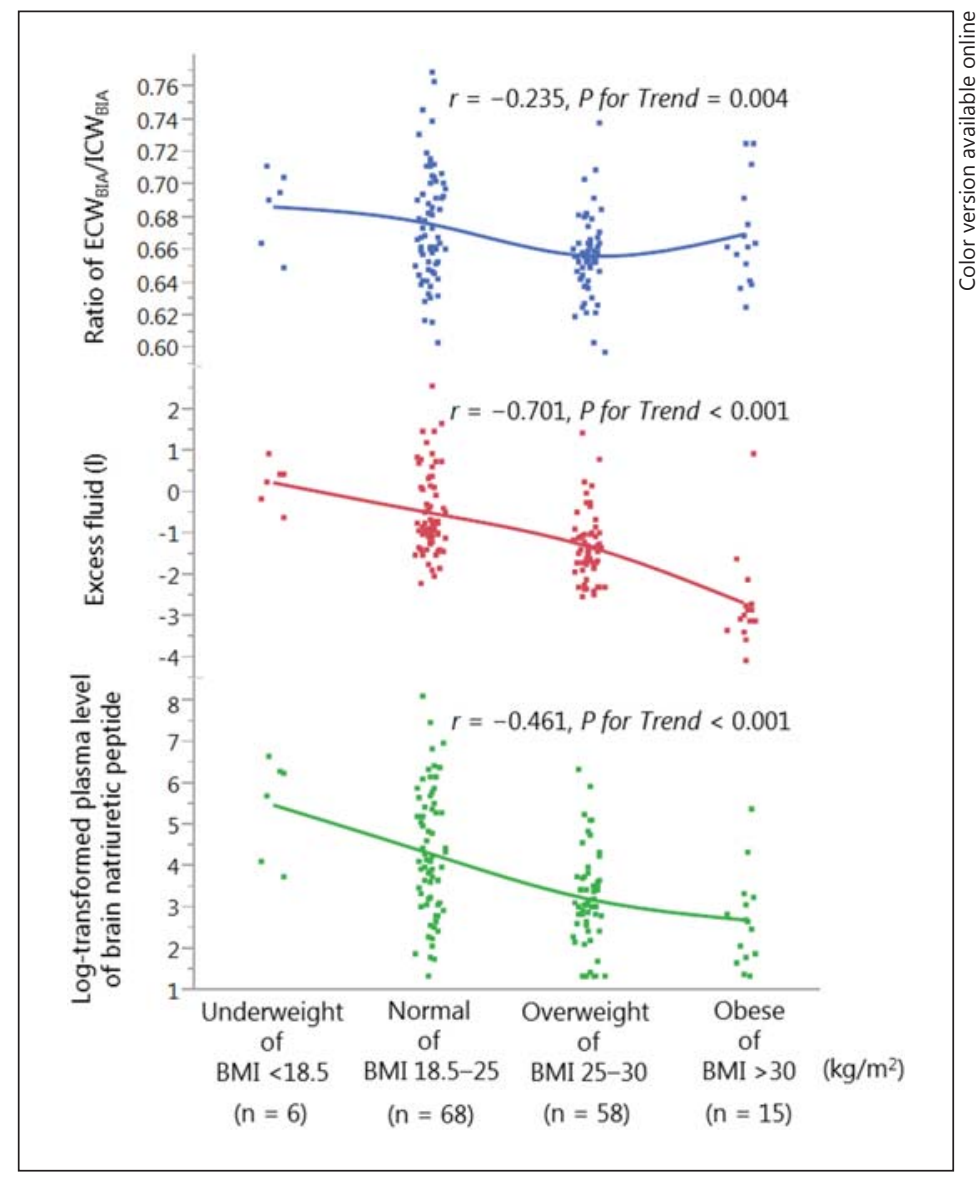

lowest tertile of DMI. In addition, the patients in the lowest tertile of DMI were more likely to have higher BNP levels, even if the ECW-to-TBW ratio was $<0.40$.

\section{Independent Factors Associated with the Log-Transformed Plasma Level of BNP}

The results of linear least squares regression analysis using the ratio of the ECW to ICW and excess fluid mass are shown in table 2 and online supplementary table $\mathrm{S} 1$. Cardiac comorbidities, BMI, and eGFR remained independently associated with BNP levels in multivariate analysis when using the ECW-to-ICW ratio, whereas age, cardiac comorbidities, and eGFR remained independently associated with the BNP levels, and significant differences between the BMI and the BNP levels disappeared, when using excess fluid mass. Multicollinearity was observed between the BMI and excess fluid mass $(r=-0.701, \mathrm{p}<0.001)$.

\section{Discussion}

In this study, the log-transformed BNP levels were significantly associated with decreased BMI, indicating that decreased body mass is associated with increased myocardial wall stress. This was related to volume expansion and the fluid volume imbalance between the ICW and ECW in patients with CKD.

The reverse epidemiology of cardiovascular risk factors was studied in patients with CKD $[16,17]$ and heart failure [18] and in the geriatric population [19]. Previous studies using 


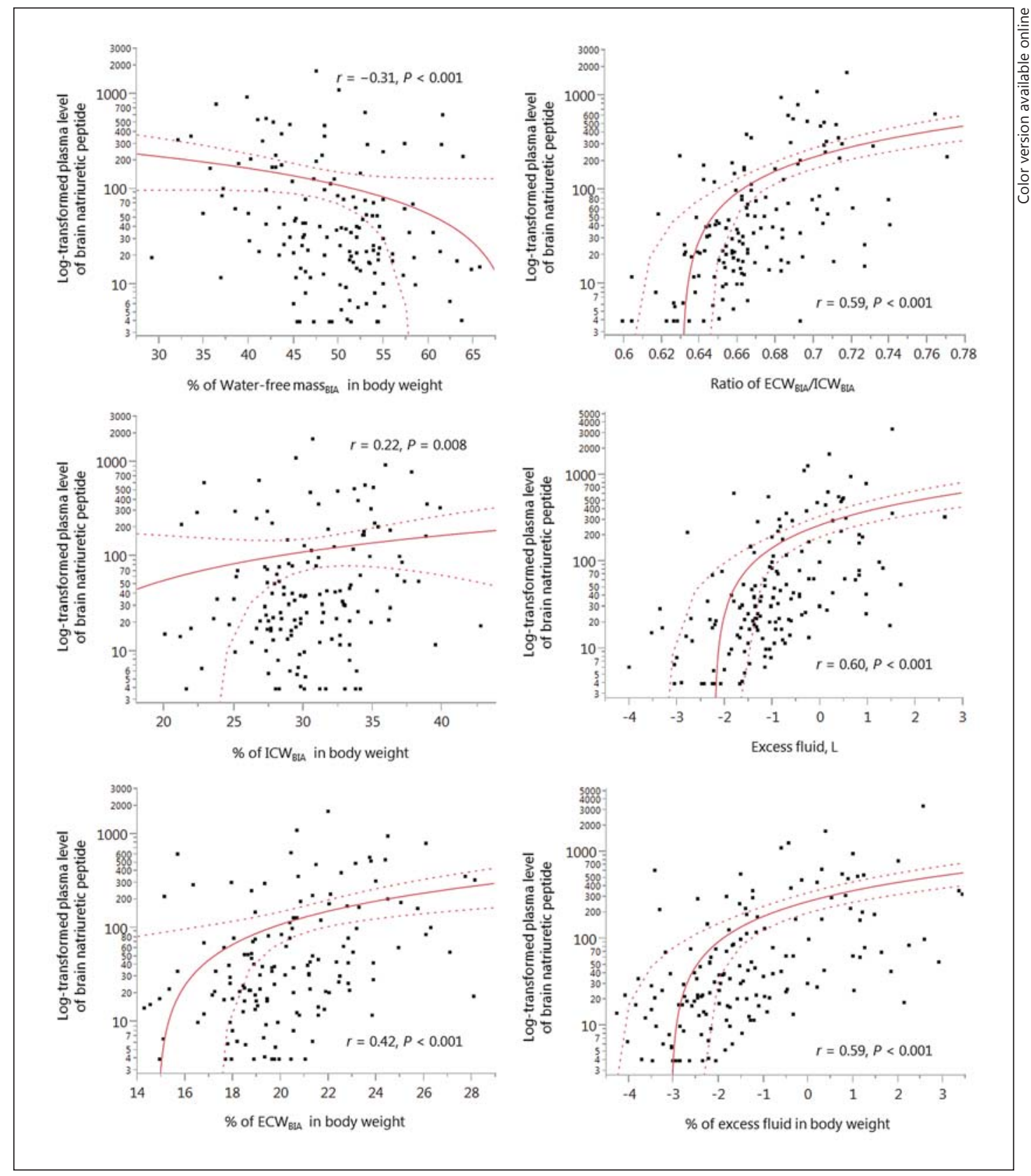

Fig. 3. Correlations between the log-transformed plasma BNP levels and the percentage of body fluid composition components in the body weight. BIA = Bioelectrical impedance analysis.

bioimpedance analysis showed that overhydration is prevalent in leaner patients undergoing dialysis therapy $[3,20]$. Overhydration might be less apparent in obese patients $[21,22]$. Malnutrition-inflammation complex syndrome in those patients may partly explain the existence of the 'obesity paradox'. Consequently, we hypothesized that leaner patients might be susceptible to hemodynamic instability. The TBW distribution is based on age, sex, and body size in everyone, including healthy subjects, and the percentage of the ECW content in the body weight shows a maximum increase in lean adults (online suppl. fig. S2 and S3). Muscle 


\section{CardioRenal Medicine}

Fig. 4. Associations of DMI and the ratio of the ECW to TBW with the measured BNP levels.

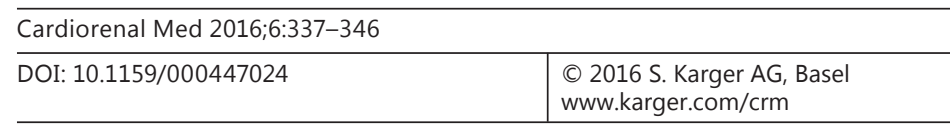

Ohashi et al: Brain Natriuretic Peptide and Body Fluid Composition in CKD

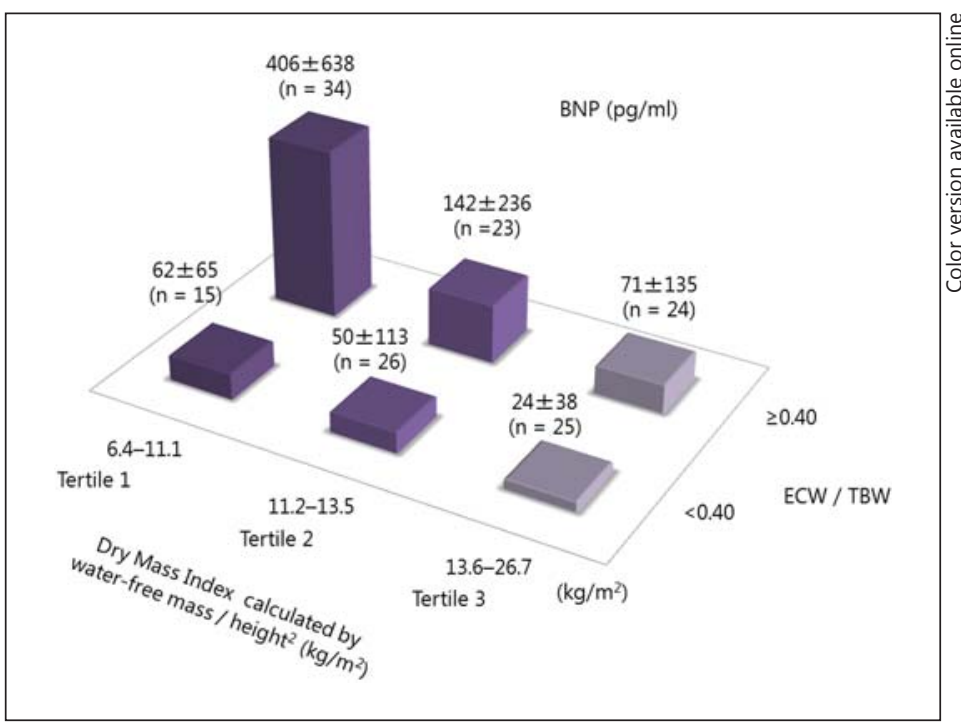

Table 2. Independent factors associated with the log-transformed plasma level of BNP using the ratio of ECW to ICW

\begin{tabular}{|c|c|c|c|c|}
\hline \multirow[t]{2}{*}{ Variables } & \multicolumn{2}{|l|}{ Univariate analysis } & \multicolumn{2}{|l|}{ Multivariate analysis $^{1}$} \\
\hline & $\beta(95 \% \mathrm{CI})$ & $\mathrm{p}$ value & $\beta(95 \% \mathrm{CI})$ & $\mathrm{p}$ value \\
\hline Age (per 10 years of age) & $0.32(0.19$ to 0.55$)$ & $<0.001$ & $0.05(-0.09$ to 0.20$)$ & 0.43 \\
\hline Presence of cardiac comorbidities & $0.45(0.48$ to 0.94$)$ & $<0.001$ & $0.41(0.46$ to 0.83$)$ & $<0.001$ \\
\hline BMI & $-0.46(-0.22$ to -0.12$)$ & $<0.001$ & $-0.19(-0.11$ to -0.03$)$ & $<0.001$ \\
\hline Pulse pressure (mm Hg) & $0.18(0.00$ to 0.03$)$ & 0.031 & $-0.02(-0.01$ to -0.00$)$ & 0.56 \\
\hline $\mathrm{eGFR}_{\mathrm{MDRD}}\left(\mathrm{ml} / \mathrm{min}\right.$ per $\left.1.73 \mathrm{~m}^{2}\right)$ & $-0.48(-0.05$ to -0.02$)$ & $<0.001$ & $-0.19(-0.02$ to -0.01$)$ & 0.003 \\
\hline Serum albumin (mg/dl) & $-0.44(-1.56$ to -0.76$)$ & $<0.001$ & $-0.13(-0.70$ to 0.03$)$ & 0.07 \\
\hline Total cholesterol (mg/dl) & $-0.17(-0.01$ to -0.00$)$ & 0.048 & $-0.09(-0.01$ to 0.00$)$ & 0.12 \\
\hline Triglyceride (mg/dl) & $-0.29(-0.01$ to -0.00$)$ & $<0.001$ & $-0.06(-0.00$ to 0.00$)$ & 0.09 \\
\hline C-reactive protein (mg/dl) & $0.18(0.01$ to 0.15$)$ & 0.030 & $0.00(-0.27$ to 0.28$)$ & 0.99 \\
\hline Ratio of $\mathrm{ECW}_{\mathrm{BIA}} / \mathrm{ICW}_{\mathrm{BIA}}($ per 0.01$)$ & $0.59(0.22$ to 0.34$)$ & $<0.001$ & $0.32(0.09$ to 0.23$)$ & $<0.001$ \\
\hline
\end{tabular}

$\mathrm{eGFR}_{\mathrm{MDRD}}=$ Estimated glomerular filtration rate by the Modification of Diet in Renal Disease method; $\beta=$ standardized regression coefficients; $\mathrm{CI}=$ confidence interval.

${ }^{1}$ Factors associated with the log-transformed plasma level of BNP in univariate analysis $(\mathrm{p}<0.10)$ were entered in the multivariable model.

mass is strongly associated with the ICW content, since approximately $73.3 \%$ of the fat-free mass is the hydration component, whereas fat mass may not be associated with the ratio of the ECW to ICW because it contains only $10 \%$ water. Hence, the slope of the ECW-to-ICW ratio with respect to the BMI was less sharp for the obese patients in this study (fig. 3). As shown in figure 4, the measured BNP levels markedly increase in patients with an ECW-to-TBW ratio $\geq 0.40$ in the lowest DMI tertile. We speculated that cell volume might be associated with the reserve capacity for volume overload in patients with fluid volume imbalance when they are exposed to fluid accumulation (online suppl. fig. S2 and S3). This vulnerability for fluid accumulation might especially occur in leaner subjects.

The causes of elevated cardiac peptide are multifactorial. Reduced kidney function decreases the fractional plasma clearance of both BNP and N-terminal pro-brain natriuretic 
peptide [23], and BMI is inversely associated with these cardiac peptides [24, 25]. These authors postulated that the lower BNP levels might result from increased receptors in adipose tissue or that a substance produced in the lean mass suppressed either synthesis or release of natriuretic peptides. However, these mechanisms cannot fully explain the actual incidence of the 'obesity paradox' in patients with CKD. Indeed, these cardiac peptides are associated with surrogate and hard clinical outcomes in asymptomatic patients with CKD [23]. In our study, our clinical physicians were committed to improving overhydration by using diuretics for the third tertile group. Intriguingly, the BNP levels and the ECW-to-ICW ratio had similar confounding factors, and the ECW-to-ICW ratio was an independently associated factor of the BNP levels. We consider that a lower BMI is correlated with excess fluid mass, which stimulated the concentration of the serum BNP. Moreover, a higher BNP level tertile is more likely to be associated with decreased serum sodium levels, which would be an indicator of increased sodium-free water. These findings possibly strengthen our hypothesis.

The ECW and ICW values should be interpreted with caution because they could distort the adjustment of the ECW content in conjunction with the decreased ICW content. Retention of the cell volume and correction of the increase in the ECW might be important for normalizing the ECW-to-ICW ratio. We recommend that malnourished patients with elevated BNP levels and higher ECW-to-ICW ratios receive nutritional support to improve the reserve capacity of the cells for volume overload.

The present study had several limitations. First, this was a cohort study that included 147 patients from a single center. Second, clearly differentiating between overhydration and malnutrition by using the ECW-to-ICW ratios is difficult. Third, the serum BNP levels were influenced by various factors in our study, such as age, BMI, and kidney function. These cofounding factors might impact on the association between the ECW-to-ICW ratio and BNP levels. Finally, we could not perform a comparison between body fluid composition, echocardiographic examination, and BNP levels; therefore, additional future studies assessing the association between body fluid composition, cardiac function, and BNP levels are required to clarify this issue.

\section{Conclusion}

The log-transformed BNP levels were significantly associated with decreased BMI, indicating that elderly and malnourished patients with CKD might be susceptible to volume overload in relation to the fluid volume imbalance between the ICW and ECW. The fluid volume imbalance between the ICW and ECW was independently associated with the logtransformed BNP levels, which might explain the reserve capacity for volume overload in patients with CKD.

\section{Statement of Ethics}

This study was approved by the Ethics Committee of Toho University Omori Medical Center, Tokyo, Japan (approval number: 25-252) and adhered to the principles of the Declaration of Helsinki. Informed consent was obtained from all study participants.

\section{Disclosure Statement}

The authors have no conflicts of interest to declare. 


\section{References}

1 Chapter 3: Management of progression and complications of CKD. Kidney Int Suppl 2013;3:73-90.

2 Sarnak MJ, Levey AS, Schoolwerth AC, Coresh J, Culleton B, Hamm LL, McCullough PA, Kasiske BL, Kelepouris E, Klag MJ, Parfrey P, Pfeffer M, Raij L, Spinosa DJ, Wilson PW; American Heart Association Councils on Kidney in Cardiovascular Disease, High Blood Pressure Research, Clinical Cardiology, and Epidemiology and Prevention: Kidney disease as a risk factor for development of cardiovascular disease: a statement from the American Heart Association Councils on Kidney in Cardiovascular Disease, High Blood Pressure Research, Clinical Cardiology, and Epidemiology and Prevention. Circulation 2003;108:2154-2169.

3 Antlanger M, Hecking M, Haidinger M, Werzowa J, Kovarik JJ, Paul G, Eigner M, Bonderman D, Hörl WH, Säemann MD: Fluid overload in hemodialysis patients: a cross-sectional study to determine its association with cardiac biomarkers and nutritional status. BMC Nephrol 2013;14:266.

4 Booth J, Pinney J, Davenport A: N-terminal proBNP - marker of cardiac dysfunction, fluid overload, or malnutrition in hemodialysis patients? Clin J Am Soc Nephrol 2010;5:1036-1040.

5 Agarwal R: Body mass index-mortality paradox in hemodialysis: can it be explained by blood pressure? Hypertension 2011;58:1014-1020.

6 Guo Q, Bárány P, Qureshi AR, Snaedal S, Heimburger O, Stenvinkel P, Lindholm B, Axelsson J: N-terminal probrain natriuretic peptide independently predicts protein energy wasting and is associated with all-cause mortality in prevalent HD patients. Am J Nephrol 2009;29:516-523.

7 Klassen P, Mazariegos M, Deurenberg P, Solomons NW, Fürst P: Hydrational status assessed by bioelectrical impedance spectroscopy and dilution methods in patients with classical dengue fever. Ann NY Acad Sci 2000; 904:163-170.

8 Ohashi Y, Tai R, Aoki T, Mizuiri S, Ogura T, Tanaka Y, Okada T, Aikawa A, Sakai K: The associations of malnutrition and aging with fluid volume imbalance between intra- and extracellular water in patients with chronic kidney disease. J Nutr Health Aging 2015;19:986-993.

9 Clinical guidelines on the identification, evaluation, and treatment of overweight and obesity in adults - the evidence report. National Institutes of Health. Obes Res 1998;6(suppl 2):51S-209S.

10 Matsuo S, Imai E, Horio M, Yasuda Y, Tomita K, Nitta K, Yamagata K, Tomino Y, Yokoyama H, Hishida A: Revised equations for estimated GFR from serum creatinine in Japan. Am J Kidney Dis 2009;53:982-992.

11 Bouillanne O, Morineau G, Dupont C, Coulombel I, Vincent JP, Nicolis I, Benazeth S, Cynober L, Aussel C: Geriatric Nutritional Risk Index: a new index for evaluating at-risk elderly medical patients. Am J Clin Nutr 2005; 82:777-783.

12 Calhoun DA, Jones D, Textor S, Goff DC, Murphy TP, Toto RD, White A, Cushman WC, White W, Sica D, Ferdinand K, Giles TD, Falkner B, Carey RM: Resistant hypertension: diagnosis, evaluation, and treatment. A scientific statement from the American Heart Association Professional Education Committee of the Council for High Blood Pressure Research. Hypertension 2008;51:1403-1419.

13 Davenport A, Sayed RH, Fan S: Is extracellular volume expansion of peritoneal dialysis patients associated with greater urine output? Blood Purif 2011;32:226-231.

14 Chamney PW, Wabel P, Moissl UM, Müller MJ, Bosy-Westphal A, Korth O, Fuller NJ: A whole-body model to distinguish excess fluid from the hydration of major body tissues. Am J Clin Nutr 2007;85:80-89.

15 Ohashi Y, Otani T, Tai R, Tanaka Y, Sakai K, Aikawa A: Assessment of body composition using dry mass index and ratio of total body water to estimated volume based on bioelectrical impedance analysis in chronic kidney disease patients. J Ren Nutr 2013;23:28-36.

16 Kalantar-Zadeh K, Block G, Horwich T, Fonarow GC: Reverse epidemiology of cardiovascular risk factors in maintenance dialysis patients. Kidney Int 2003;63:793-808.

17 Kovesdy CP, Anderson JE: Reverse epidemiology in patients with chronic kidney disease who are not yet on dialysis. Semin Dial 2007;20:566-569.

18 Kalantar-Zadeh K, Block G, Horwich T, Fonarow GC: Reverse epidemiology of conventional cardiovascular risk factors in patients with chronic heart failure. J Am Coll Cardiol 2004;43:1439-1444.

19 Ahmadi SF, Streja E, Zahmatkesh G, Streja D, Kashyap M, Moradi H, Molnar MZ, Reddy U, Amin AN, Kovesdy $\mathrm{CP}$, Kalantar-Zadeh K: Reverse epidemiology of traditional cardiovascular risk factors in the geriatric population. J Am Med Dir Assoc 2015;16:933-939.

20 O'Lone EL, Visser A, Finney H, Fan SL: Clinical significance of multi-frequency bioimpedance spectroscopy in peritoneal dialysis patients: independent predictor of patient survival. Nephrol Dial Transplant 2014;29:1430-1437.

21 Tapolyai M, Faludi M, Reti V, Lengvárszky Z, Szarvas T, Berta K: Dialysis patients' fluid overload, antihypertensive medications, and obesity. ASAIO J 2011;57:511-515.

22 Tapolyai M, Faludi M, Réti V, Lengvárszky Z, Szarvas T, Berta K: Volume estimation in dialysis patients: the concordance of brain-type natriuretic peptide measurements and bioimpedance values. Hemodial Int 2013;17:406-412.

23 Colbert G, Jain N, de Lemos JA, Hedayati SS: Utility of traditional circulating and imaging-based cardiac biomarkers in patients with predialysis CKD. Clin J Am Soc Nephrol 2015;10:515-529.

24 Das SR, Drazner MH, Dries DL, Vega GL, Stanek HG, Abdullah SM, Canham RM, Chung AK, Leonard D, Wians FH Jr, de Lemos JA: Impact of body mass and body composition on circulating levels of natriuretic peptides: results from the Dallas Heart Study. Circulation 2005;112:2163-2168.

25 Wang TJ, Larson MG, Levy D, Benjamin EJ, Leip EP, Wilson PW, Vasan RS: Impact of obesity on plasma natriuretic peptide levels. Circulation 2004;109:594-600. 